\title{
Allergic asthma exhaled breath metabolome: A challenge for comprehensive two-dimensional gas chromatography
}

\author{
M. Caldeira ${ }^{a, b}$, R. Perestrelo ${ }^{a, b}$, A.S. Barros ${ }^{a}$, M.J. Bilelo ${ }^{c}$, A. Morête $^{c}$, J.S. Câmara ${ }^{b}$, S.M. Rocha ${ }^{a, *}$ \\ a QOPNA, Departamento de Química, Universidade de Aveiro, 3810-193 Aveiro, Portugal

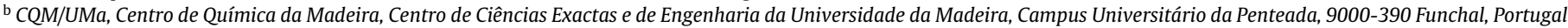 \\ ${ }^{\mathrm{c}}$ Hospital Infante D. Pedro E.P.E, Avenida Artur Ravara, 3814-501 Aveiro, Portugal
}

\section{A R T I C L E I N F O}

\section{Article history:}

Received 12 March 2012

Received in revised form 5 July 2012

Accepted 9 July 2012

Available online 16 July 2012

\section{Keywords:}

Allergic asthma

Exhaled breath

Volatile metabolites

Headspace-solid phase microextraction

Comprehensive two-dimensional gas

chromatography-time of flight mass

spectrometry

\begin{abstract}
A B S T R A C T
Allergic asthma represents an important public health issue, most common in the paediatric population, characterized by airway inflammation that may lead to changes in volatiles secreted via the lungs. Thus, exhaled breath has potential to be a matrix with relevant metabolomic information to characterize this disease. Progress in biochemistry, health sciences and related areas depends on instrumental advances, and a high throughput and sensitive equipment such as comprehensive two-dimensional gas chromatography-time of flight mass spectrometry (GC $\times$ GC-ToFMS) was considered. GC $\times$ GC-ToFMS application in the analysis of the exhaled breath of 32 children with allergic asthma, from which 10 had also allergic rhinitis, and 27 control children allowed the identification of several hundreds of compounds belonging to different chemical families. Multivariate analysis, using Partial Least Squares-Discriminant Analysis in tandem with Monte Carlo Cross Validation was performed to assess the predictive power and to help the interpretation of recovered compounds possibly linked to oxidative stress, inflammation processes or other cellular processes that may characterize asthma. The results suggest that the model is robust, considering the high classification rate, sensitivity, and specificity. A pattern of six compounds belonging to the alkanes characterized the asthmatic population: nonane, 2,2,4,6,6-pentamethylheptane, decane, 3,6-dimethyldecane, dodecane, and tetradecane. To explore future clinical applications, and considering the future role of molecular-based methodologies, a compound set was established to rapid access of information from exhaled breath, reducing the time of data processing, and thus, becoming more expedite method for the clinical purposes.
\end{abstract}

(c) 2012 Published by Elsevier B.V.

\section{Introduction}

Asthma is a complex inflammatory disorder characterized by allergic inflammation, smooth muscle contraction, bronchial hyperresponsiveness, hypertrophy and hyperplasia of smooth muscle, hypersecretion of bronchial mucus, activation of mast cells, eosinophils, lymphocytes, epithelial cells, macrophages, disruption of the bronchial epithelium and production of free radicals with variable symptoms (e.g. cough, dyspnoea, wheezing, chest pain)[1]. Allergic asthma is the most common form of asthma and is increasing considerably, in developed countries such that it is now one of the commonest chronic disorders in the world, and is also associated with high direct and indirect health costs, especially related with diagnosis and treatment.

In recent years, non-invasive techniques that may be useful for the assessment of airway inflammation have been found in the analysis of exhaled breath. Inflammation plays a critical role

\footnotetext{
* Corresponding author. Tel.: +351 234401524; fax: +351 234370084

E-mail address: smrocha@ua.pt (S.M. Rocha).
}

in many physiological changes of the body including inflammatory lung diseases like asthma. Inflammation is accompanied by oxidative stress and subsequently lipid peroxidation and during this process polyunsaturated fatty acids are converted into volatiles that are secreted via the lungs. Hundreds of different volatiles are present in human breath, and their relative concentrations may alter via the disease [2]. Exhaled breath has been studied using one-dimensional gas chromatographic (1D-GC) process in lung diseases, such as asthma [2,3], cystic fibrosis [4] and lung cancer [5,6]. Although such approach often provides satisfying analytical results an in-depth chromatogram analysis frequently indicates that some peaks are the result of two or more co-eluting compounds. Comprehensive two dimensional gas chromatography $(\mathrm{GC} \times \mathrm{GC})$ employs two orthogonal mechanisms to separate the constituents of the sample within a single analysis, based on the application of two GC columns coated with different stationary phases, which increases peak capacity as a result of the product of the peak capacity of the two dimensions. For example, a non-polar/polar phase combination (NP/P), connected in series through a modulator interface achieves this goal. For instance, using a cryogenic modulator, the interface samples small (several seconds) portions of the first 
Table 1

Characteristics of the studied population: allergic asthma and control children.

\begin{tabular}{|c|c|c|c|c|c|c|}
\hline & & \multicolumn{3}{|c|}{ Allergic asthma $(n=32)$} & \multicolumn{2}{|l|}{ Control $(n=27)$} \\
\hline \multicolumn{2}{|c|}{ Age in years (range/median) } & \multicolumn{3}{|c|}{$4-16 / 9$} & \multicolumn{2}{|l|}{$3-6 / 5$} \\
\hline \multicolumn{2}{|c|}{ Gender (male/female) } & \multicolumn{2}{|c|}{$18 / 14$} & & \multicolumn{2}{|l|}{$15 / 12$} \\
\hline \multicolumn{7}{|c|}{ Pathology } \\
\hline \multicolumn{2}{|c|}{ Allergic asthma (AA) } & \multicolumn{2}{|c|}{$22(69 \%)$} & & \multicolumn{2}{|l|}{-} \\
\hline Allergic asth & allergic rhinitis $(A A+A R)$ & & $31 \%)$ & & - & \\
\hline \multicolumn{7}{|c|}{ Allergens $^{\mathrm{a}}$} \\
\hline \multicolumn{2}{|l|}{ Dust mite } & \multicolumn{2}{|c|}{$18(56 \%)$} & & \multicolumn{2}{|l|}{-} \\
\hline \multicolumn{2}{|c|}{ Dust mite + gramineae } & \multicolumn{2}{|c|}{$5(16 \%)$} & & \multicolumn{2}{|l|}{-} \\
\hline \multicolumn{2}{|c|}{ Gramineae } & \multicolumn{2}{|c|}{$4(13 \%)$} & & \multicolumn{2}{|l|}{-} \\
\hline \multicolumn{2}{|c|}{ Dust mite + cat fur + gramineae } & \multicolumn{2}{|c|}{$2(6 \%)$} & & \multicolumn{2}{|l|}{-} \\
\hline \multicolumn{2}{|c|}{ Dust mite + cat fur } & \multicolumn{2}{|c|}{$1(3 \%)$} & & \multicolumn{2}{|l|}{-} \\
\hline \multicolumn{2}{|c|}{ Gramineae + cat fur } & \multicolumn{2}{|c|}{$1(3 \%)$} & & \multicolumn{2}{|l|}{ - } \\
\hline \multicolumn{2}{|c|}{ Dust mite + cockroach } & \multicolumn{2}{|c|}{$1(3 \%)$} & & - & \\
\hline Therapy & & & & & & \\
\hline Corticosteroid & Leukotriene receptor antagonist & Bronchodilator & Anti-histamine & Nasal corticosteroid & Allergic asthma $(n=32)$ & Control $(n=27)$ \\
\hline $\mathrm{x}$ & $\mathrm{x}$ & $\mathrm{x}$ & - & - & $1(3 \%)$ & - \\
\hline $\mathrm{x}$ & - & $\mathrm{x}$ & - & - & $9(28 \%)$ & - \\
\hline $\mathrm{x}$ & $\mathrm{x}$ & - & - & - & $5(16 \%)$ & - \\
\hline- & $\mathrm{x}$ & - & $\mathrm{x}$ & $\mathrm{x}$ & $2(6 \%)$ & - \\
\hline- & - & $\mathrm{x}$ & $\mathrm{x}$ & - & $5(16 \%)$ & - \\
\hline- & $\mathrm{x}$ & $\mathrm{x}$ & - & - & $1(3 \%)$ & - \\
\hline- & - & - & $\mathrm{x}$ & $\mathrm{x}$ & $2(6 \%)$ & - \\
\hline- & $\mathrm{x}$ & - & $\mathrm{x}$ & - & $1(3 \%)$ & - \\
\hline No therapy & & - & & & $6(19 \%)$ & \\
\hline
\end{tabular}

a Results obtained by prick-tests.

dimension $\left({ }^{1} \mathrm{D}\right)$ eluate by cryofocusing, and re-injects them into the second column $\left({ }^{2} \mathrm{D}\right)$. Each ${ }^{1} \mathrm{D}$ peak is modulated several times, largely preservating the ${ }^{1} \mathrm{D}$ separation. Co-eluting compounds from ${ }^{1} \mathrm{D}$ undergo additional separation on ${ }^{2} \mathrm{D}[7]$. Sensitivity and limits of detection are improved due to focusing of the peak in the modulator and separation of analytes from chemical background [8] compared to 1D-GC. ToFMS (time-of-flight mass spectrometry) brings several advantages such as full mass spectra acquisition at trace level sensitivity and mass spectral continuity, which allows for deconvolution of spectra of co-eluted peaks [9]. To the best of our knowledge, GC $\times$ GC-ToFMS methodology has never been reported before to study allergic asthma exhaled breath volatile composition. However, GC $\times$ GC-ToFMS has been used with multibed sorption trap for exploring human exhaled breath volatile composition [10], and searching potential biomarkers for active smoking [11], and combined with automated needle trap for breath analysis of patients undergoing cardiac surgery [12]. These studies revealed the potential of this technique in breath analysis. Thus, this study aims to obtain a deeper knowledge of allergic asthma based on exhaled breath analysis using a previously developed HS-SPME extraction technique, as well as several other exhaled breath sampling parameters [3], combined with GC $\times$ GC-ToFMS system. The first step was to check the separation potential of GC $\times$ GC-ToFMS and sensitivity issues, important parameters in exhaled breath analysis, a complex matrix with several compounds in the micromolar to nanomolar range [13]. Secondly, Partial Least Squares-Discriminant Analysis (PLS-DA) and Monte Carlo Cross Validation (MCCV) were performed to assess both the predictive power and classification models robustness. Moreover PLS-DA regression vectors were used to help understand metabolic variations important to class discrimination.

\section{Experimental}

\subsection{Standards and materials}

Several reagents were used to perform this study: linear alkanes $\left(C_{8}-C_{20}\right)$ in hexane (99.5\%, Fluka, Madrid, Spain), linear alkenes
$\left(\mathrm{C}_{8}-\mathrm{C}_{20}\right)(98 \%$, Sigma-Aldrich, Madrid, Spain), aldehydes: hexanal (98\%, Sigma-Aldrich, Madrid, Spain), (E)-2-nonenal (95\%, Acros Organics, Geel Belgium), decanal (98\%, Sigma-Aldrich, Madrid, Spain), ketones: 3-heptanone (97\%, Sigma-Aldrich, Madrid, Spain), 5-methyl-3-heptanone (94\%, Sigma-Aldrich, Madrid, Spain), $3-$ octanone (98\%, Sigma-Aldrich, Madrid, Spain), absolute ethanol was supplied by Panreac (99.5\%, analytical grade, Barcelone, Spain). Ultra pure water was obtained from a Milli-Q system from Millipore (Milford, MA, USA).

For the sensitivity studies, a stock solution of each standard ( $1 \mathrm{~g} / \mathrm{L}$ ) was prepared in absolute ethanol and made up to volume, and from this a solution of $100 \mathrm{mg} / \mathrm{L}$ was set up. A working solution was prepared to yield different concentrations and to reproduce a two-phase system (headspace and coating fibre), as in breath analysis, $5 \mu \mathrm{L}$ was added to a $120 \mathrm{~mL}$ SPME flask and sealed with an aluminium crimp cap with a vial was capped with a PTFE septum (Chromacol, Hertfordshire, UK), and concentrations ranged from 20 to $200 \times 10^{3} \mathrm{pg} / \mathrm{L}$.

The SPME holder for manual sampling and fibre were purchased from Supelco (Aldrich, Bellefonte, PA, USA). The SPME device included a fused silica fibre coating partially cross-linked with 50/30 $\mu \mathrm{m}$ divinylbenzene-carboxen-poly(dimethylsiloxane) (DVB/CAR/PDMS). Prior to use, the SPME fibre was conditioned at $270^{\circ} \mathrm{C}$ for $60 \mathrm{~min}$ in the GC injector, according to the manufacturer's recommendations. Then, the fibre was daily conditioned for $10 \mathrm{~min}$ at $250^{\circ} \mathrm{C}$.

\subsection{Samples}

A group of 32 children with allergic asthma, from which 10 had allergic asthma and allergic rhinitis, and 27 healthy control children volunteered for this study $(n=59)$. The characteristics of the patients and controls are presented in Table 1. A naive patient was also included in this study. This patient was a 9 years old female child that had never taken an asthma drug and was diagnosed by physicians with allergic asthma based on symptoms history and skin prick tests were performed being positive for dust mites. After the first consult, this child was prescribed a combination 
of anti-histamine and a leukotriene receptor antagonist. The 59 individuals correspond to a total of 69 exhaled breath samples. Usually, each individual corresponds to one breath sample, except for an allergic asthma child that was collected up to 6 times in different locations/time periods and for the naive exhaled breath was collected at four different moments.

All parents signed an informed consent for participation in the study. The children with allergic asthma were recruited from the outpatient clinic of paediatric immunoalergology and from the immunoalergology departments of the Hospital Infante D. Pedro E.P.E (Aveiro, Portugal) whilst healthy controls were recruited at two local daycare facilities that presented no asthma episodes or symptoms. Asthma diagnosis was made based on clinical symptoms and exams (skin prick tests and IgE values). Appropriate therapy was prescribed by the patient's own physician. The allergic asthma population represented a controlled asthma status, with exception of a naive child (see Section 3.3). No restrictions were applied regarding drugs or diet, and each allergic asthma and control groups were sampled in two distinct locations (in a total of four collections sites). The study was approved by the hospital ethics committee and the daycare administration.

\subsection{Breath sampling}

The breath sampling parameters were previously optimized [3]. Exhaled breath was collected in $1 \mathrm{~L}$ Tedlar $^{\circledR}$ bags. Children were asked to cleanse their mouth with water before sampling. Subsequently, children were instructed to inhale and exhaled normally and then exhale deeply into the Tedlar ${ }^{\circledR}$ bag previously holding their breath for $5 \mathrm{~s}$. The collection method was successfully done by all volunteers. Each subject provided one sample using a disposable mouthpiece. Before collecting exhaled breath, all bags were thoroughly cleaned to remove residual contaminants by flushing with high purity nitrogen gas. The bags were transported to the laboratory and the analysis was performed to a maximum of six hours as recommended by Mochalski et al. [14]. On average, the analysis was performed after $2-3 \mathrm{~h}$ after sampling. The bags were stored at $22^{\circ} \mathrm{C}$.

\subsection{HS-SPME methodology}

The SPME coating fibre and the experimental parameters were adopted from a methodology previously developed in our laboratory [3]: DVB/CAR/PDMS fibre, and an extraction temperature and time of $22^{\circ} \mathrm{C}$ and $60 \mathrm{~min}$, respectively. Following the extraction procedure, the SPME fibre was retracted from the Tedlar ${ }^{\circledR}$ bag and inserted in the GC system injection port. The HS-SPME methodology was also applied to selected standards to verify the GC $\times$ GC sensitivity as previously described in Section 2.1. Each breath represents a single sample, and was analysed once. To verify the absence of any carry over, blanks (that corresponds to the analysis of the coating fibre not submitted to any extraction procedure and Tedlar ${ }^{\circledR}$ bags) were performed.

\subsection{GC $\times$ GC-ToFMS analysis}

After the extraction/concentration step, the SPME coating fibre was manually introduced into the GC $\times$ GC-ToFMS injection port at $250^{\circ} \mathrm{C}$. The injection port was lined with a $0.75 \mathrm{~mm}$ I.D. splitless glass liner. Splitless injections were used ( $2 \mathrm{~min}$ ). LECO Pegasus 4D (LECO, St. Joseph, MI, USA) GC $\times$ GC-ToFMS system consisted of an Agilent GC 7890A gas chromatograph, with a dual stage jet cryogenic modulator (licensed from Zoex) and a secondary oven. The detector was a high-speed ToF mass spectrometer. An HP-5 column $(30 \mathrm{~m} \times 0.32 \mathrm{~mm}$ I.D., $0.25 \mu \mathrm{m}$ film thickness, $5 \%$ Phenyl-methylpolysiloxane, J\&W Scientific Inc., Folsom, CA, USA) was used as ${ }^{1} \mathrm{D}$ column and a DB-FFAP $(0.79 \mathrm{~m} \times 0.25 \mathrm{~mm}$ I.D., $0.25 \mu \mathrm{m}$ film thickness, nitroterephthalic acid modified polyethylene glycol, J\&W Scientific Inc., Folsom, CA, USA) was used as ${ }^{2} \mathrm{D}$ column. The carrier gas was helium at a constant flow rate of $2.50 \mathrm{~mL} / \mathrm{min}$. The GC $\times$ GC-ToFMS injection port was at $250^{\circ} \mathrm{C}$. The primary oven temperature programme was: initial temperature $35^{\circ} \mathrm{C}$ (hold $\left.1 \mathrm{~min}\right)$, raised to $40^{\circ} \mathrm{C}\left(1^{\circ} \mathrm{C} / \mathrm{min}\right)$, and finally rose to $220^{\circ} \mathrm{C}\left(7^{\circ} \mathrm{C} / \mathrm{min}\right)$ and hold for $1 \mathrm{~min}$. The secondary oven temperature programme was $15^{\circ} \mathrm{C}$ offset above the primary oven. The MS transfer line temperature was $250^{\circ} \mathrm{C}$ and the MS source temperature was $250^{\circ} \mathrm{C}$. A $6 \mathrm{~s}$ modulation time with a $30^{\circ} \mathrm{C}$ secondary oven temperature offset (above primary oven) was chosen to be a suitable compromise as it maintained the ${ }^{1} \mathrm{D}$ separation, maximized the ${ }^{2} \mathrm{D}$ resolution, and avoiding wrap-around effect (the elution time of a pulsed solute exceeds the modulation period) for compounds that were late to elute from the ${ }^{2} \mathrm{D}$. Ideally, all peaks must be detected before the subsequent re-injection and, hence, ${ }^{2} t_{R}$ must be equal or less than the modulation period $[15,16]$. The ToFMS was operated at a spectrum storage rate of 125 spectra/s. The mass spectrometer was operated in the EI mode at $70 \mathrm{eV}$ using a range of $m / z 35-350$ and the detector voltage was $-1695 \mathrm{~V}$. Total ion chromatograms (TIC) were processed using the automated data processing software ChromaToF (LECO) at signal-to-noise threshold of 80 . Contour plots were used to evaluate the separation general quality and for manual peak identification. In order to identify the different compounds, the mass spectrum of each compound detected was compared to those in mass spectral libraries of one home-made (using standards) and two commercial databases (Wiley 275 and US National Institute of Science and Technology (NIST) V. 2.0 - Mainlib and Replib). The identification was also supported by experimentally determining the retention index (RI) values that were compared, when available, with values reported in literature for chromatographic columns similar to that used as the ${ }^{1} \mathrm{D}$ column and whenever available compared to RI values obtained by GC $\times$ GC [17-52]. For determination of RI values a $C_{8}-C_{20} n$ alkanes series was used, calculated according to the Van den Dool and Kratz equation [53]. The majority ( $>90 \%$ ) of the identified compounds presented similarity matches $>850$. The GC $\times$ GC area data was used as an approach to estimate the relative content of each volatile component of exhaled breath.

\subsection{Multivariate analysis}

A full dataset comprises 134 metabolites belonging to selected chemical families. A sub-set of 23 metabolites was also established by the compounds simultaneously identified by GC $\times$ GC-ToFMS, and those previously reported in a allergic asthma study [3] (indicated in Table 2). Partial Least Squares (PLS) is a widely used procedure for both regression and classification purposes. Concerning the classification application of PLS, known as Partial Least Squares-Discriminant Analysis (PLS-DA) [54], the most common approach is to use a $\mathbf{Y}$ matrix containing dummy variables which defines sample memberships to pre-defined groups and allow extracting relevant information/variability that could describe the reasons for the observed patterns (clusters). This methodology allows one to understand which variables (metabolites) contribute the most for the observed separation. Each sample was mean normalized and UV (unit variance) scaled which is a data pre-treatment process that gives to variables the same weight. The PLS-DA was applied to volatile metabolites (both datasets: 23 and 134 metabolites) tentatively identified by HS-SPME/GC $\times$ GC-ToFMS in all exhaled breath samples (69) and for classification purposes two groups were used (control and asthma).

The classification model complexity (number of latent variables) of the full dataset (134 metabolites) was computed, as well as 
Table 2

List of volatile compounds identified by GC $\times$ GC-ToFMS in exhaled breath of allergic asthma and control children.

\begin{tabular}{|c|c|c|c|c|c|c|c|}
\hline Peak number & ${ }^{1} t_{\mathrm{R}}{ }^{\mathrm{a}}(\mathrm{s})$ & ${ }^{2} t_{\mathrm{R}}{ }^{\mathrm{a}}(\mathrm{s})$ & Compounds & CAS number & $\mathrm{RI}_{\text {calc }}{ }^{\mathrm{b}}$ & $\mathrm{RI}_{\text {lit. }}{ }^{\mathrm{c}}(\mathrm{GC})$ & $\mathrm{RI}_{\text {lit. }}{ }^{\mathrm{d}}(\mathrm{GC} \times \mathrm{GC})$ \\
\hline \multicolumn{8}{|c|}{ Alkanes } \\
\hline \multicolumn{8}{|c|}{ Linear and ramified } \\
\hline 1 & 138 & 0.48 & Hexane & $110-54-3$ & 600 & 600 & 600 \\
\hline 4 & 210 & 0.52 & 2,4-Dimethylhexane & $589-43-5$ & 727 & 736 & 729 \\
\hline 7 & 252 & 0.54 & Octane & $111-65-9$ & 800 & 800 & 800 \\
\hline 11 & 276 & 0.55 & 2,2,4-Trimethylhexane $\mathrm{e}^{\mathrm{e}}$ & $921-47-1$ & 817 & 810 & $-{ }^{\mathrm{f}}$ \\
\hline 12 & 288 & 0.55 & 2,4-Dimethylheptane $\mathrm{e}^{\mathrm{e}}$ & $2213-23-2$ & 817 & 820 & 822 \\
\hline 13 & 318 & 0.56 & 4-Ethyl-2-methylhexane & $3074-75-7$ & 831 & 833 & - \\
\hline 15 & 366 & 0.58 & Alkane isomer $(m / z 43,57,85)$ & - & 853 & - & - \\
\hline 20 & 468 & 0.56 & Nonane & $111-84-2$ & 900 & 900 & 900 \\
\hline 22 & 504 & 0.55 & Alkane isomer $(m / z 43,57,85)$ & - & 919 & - & - \\
\hline 23 & 516 & 0.55 & 2,4-Dimethyloctane $\mathrm{e}^{\mathrm{e}}$ & $15869-93-9$ & 925 & 924 & - \\
\hline 24 & 528 & 0.56 & 3-Ethyl-3-methylheptane ${ }^{\mathrm{e}}$ & $17302-01-1$ & 932 & - & 942 \\
\hline 26 & 540 & 0.55 & 2,6-Dimethyloctane & 2051-30-1 & 938 & 936 & 933 \\
\hline 28 & 552 & 0.55 & 3-Ethyl-2-methylheptane & $14676-29-0$ & 944 & - & 942 \\
\hline 30 & 558 & 0.55 & Alkane isomer $(m / z 57,43,71)$ & - & 947 & - & - \\
\hline 31 & 564 & 0.55 & Alkane isomer $(m / z 43,57,71)$ & - & 950 & - & - \\
\hline 33 & 576 & 0.56 & 4-Ethyloctane & $15869-86-0$ & 957 & 956 & - \\
\hline 36 & 582 & 0.55 & 4-Methylnonane & $17301-94-9$ & 960 & 962 & 956 \\
\hline 38 & 588 & 0.54 & Alkane isomer $(m / z 57,43,85)$ & - & 963 & - & - \\
\hline 40 & 594 & 0.55 & Alkane isomer $(m / z 57,43,71)$ & - & 966 & - & - \\
\hline 42 & 600 & 0.55 & 2-Methylnonane & $871-83-0$ & 969 & 970 & - \\
\hline 43 & 606 & 0.55 & Alkane isomer $(m / z 57,43,41)$ & - & 972 & - & - \\
\hline 45 & 612 & 0.55 & 3-Methylnonane $\mathrm{e}^{\mathrm{e}}$ & 5911-04-6 & 975 & 976 & - \\
\hline 52 & 636 & 0.54 & 2,2,4,6,6-Pentamethylheptane & $13475-82-6$ & 988 & 997 & - \\
\hline 58 & 660 & 0.56 & Decane $^{\mathrm{e}}$ & 124-18-5 & 1000 & 1000 & 1000 \\
\hline 60 & 672 & 0.54 & Alkane isomer $(m / z 57,41,71)$ & - & 1008 & - & - \\
\hline 61 & 720 & 0.54 & 3,9-Dimethylnonane $\mathrm{e}^{\mathrm{e}}$ & $17302-32-8$ & 1039 & 1038 & \\
\hline 64 & 756 & 0.54 & 3,6-Dimethyldecane $\mathrm{e}^{\mathrm{e}}$ & $17301-30-3$ & 1062 & 1063 & - \\
\hline 66 & 768 & 0.54 & Alkane isomer $(m / z 57,43,85)$ & - & 1070 & - & - \\
\hline 68 & 774 & 0.55 & 3-Methyldecane $\mathrm{e}^{\mathrm{e}}$ & $13151-34-3$ & 1073 & 1073 & - \\
\hline 72 & 786 & 0.55 & Alkane isomer $(m / z 57,43,71)$ & - & 1081 & - & - \\
\hline 74 & 798 & 0.55 & 2-Methyldecane $\mathrm{e}^{\mathrm{e}}$ & $6975-98-0$ & 1089 & 1073 & - \\
\hline 76 & 804 & 0.55 & Alkane isomer $(m / z 43,71,57)$ & - & 1093 & - & - \\
\hline 81 & 822 & 0.55 & Undecane $e^{\mathrm{e}}$ & $1120-21-4$ & 1100 & 1100 & 1100 \\
\hline 84 & 864 & 0.56 & 2,3-Dimethyldecane $\mathrm{e}^{\mathrm{e}}$ & $1632-71-9$ & 1135 & 1118 & - \\
\hline 86 & 876 & 0.56 & Alkane isomer $(m / z 57,43,71)$ & - & 1144 & - & - \\
\hline 87 & 894 & 0.55 & 5-Methylundecane ${ }^{\mathrm{e}}$ & $1632-70-8$ & 1157 & 1154 & - \\
\hline 89 & 906 & 0.57 & Alkane isomer $(m / z 57,43,71)$ & - & 1166 & - & - \\
\hline 90 & 912 & 0.57 & 3,9-Dimethylundecane $\mathrm{e}^{\mathrm{e}}$ & $7045-71-8$ & 1170 & 1165 & - \\
\hline 95 & 948 & 0.57 & Dodecane $\mathrm{e}^{\mathrm{e}}$ & $112-40-3$ & 1200 & 1200 & 1200 \\
\hline 96 & 960 & 0.58 & Alkane isomer $(m / z 57,71,43)$ & - & 1206 & - & - \\
\hline 99 & 966 & 0.57 & Alkane isomer $(m / z 57,43,71)$ & - & 1211 & - & - \\
\hline 100 & 972 & 0.56 & 2,5,6-Trimethyldecane $\mathrm{e}^{\mathrm{e}}$ & $17301-28-9$ & 1216 & 1206 & - \\
\hline 101 & 978 & 0.57 & Alkane isomer $(m / z 57,43,71)$ & - & 1221 & - & - \\
\hline 104 & 996 & 0.56 & Alkane isomer $(m / z 57,43,71)$ & - & 1236 & - & - \\
\hline 106 & 1002 & 0.57 & Alkane isomer $(m / z 57,43,71)$ & - & 1241 & - & - \\
\hline 107 & 1008 & 0.57 & 6-Methyldodecane & $6044-71-9$ & 1246 & 1253 & - \\
\hline 108 & 1020 & 0.57 & Alkane isomer $(m / z 43,57,71)$ & - & 1256 & - & - \\
\hline 110 & 1044 & 0.55 & Alkane isomer $(m / z 57,43,71)$ & - & 1276 & - & - \\
\hline 111 & 1050 & 0.55 & 4-Ethylundecane & $17312-59-3$ & 1281 & - & - \\
\hline 112 & 1056 & 0.57 & Alkane isomer $(m / z 57,43,71)$ & - & 1286 & - & - \\
\hline 113 & 1062 & 0.55 & Alkane isomer $(m / z 57,71,43)$ & - & 1291 & - & - \\
\hline 115 & 1068 & 0.56 & Alkane isomer $(m / z 43,57,71)$ & - & 1296 & - & - \\
\hline 117 & 1074 & 0.57 & Tridecane $^{\mathrm{e}}$ & 629-50-5 & 1300 & 1300 & 1300 \\
\hline 120 & 1092 & 0.57 & 2,2-Dimethyldodecane & 49598-54-1 & 1316 & 1315 & - \\
\hline 121 & 1104 & 0.57 & Alkane isomer $(m / z 57,43,71)$ & - & 1327 & - & - \\
\hline 122 & 1110 & 0.57 & Alkane isomer $(m / z 57,43,71)$ & - & 1332 & - & - \\
\hline 123 & 1116 & 0.57 & Alkane isomer $(m / z 57,71,43)$ & - & 1337 & - & - \\
\hline 124 & 1128 & 0.57 & 3-Ethyl-3-methylundecane $\mathrm{e}^{\mathrm{e}}$ & - & 1348 & 1347 & - \\
\hline 125 & 1152 & 0.60 & 2-Methyltridecane $\mathrm{e}^{\mathrm{e}}$ & $6418-41-3$ & 1369 & 1371 & - \\
\hline 126 & 1158 & 0.59 & Alkane isomer $(m / z 57,43,71)$ & - & 1374 & - & - \\
\hline 127 & 1170 & 0.61 & Alkane isomer $(m / z 57,43,71)$ & - & 1385 & - & - \\
\hline 128 & 1188 & 0.61 & Tetradecane $^{\mathrm{e}}$ & $629-59-4$ & 1400 & 1400 & 1400 \\
\hline 130 & 1284 & 0.58 & Alkane isomer $(m / z 57,43,85)$ & - & 1489 & - & - \\
\hline 131 & 1290 & 0.58 & 6,6-Diethyldodecane & - & 1495 & 1498 & - \\
\hline 132 & 1296 & 0.64 & Pentadecane $\mathrm{e}^{\mathrm{e}}$ & $629-62-9$ & 1500 & 1500 & 1500 \\
\hline 133 & 1302 & 0.59 & 5-Ethyl-5-methyltridecane & - & 1507 & 1511 & - \\
\hline 134 & 1338 & 0.61 & 3-Ethyl-3-methyltridecane & - & 1544 & 1549 & - \\
\hline \multicolumn{8}{|l|}{ Cycloalkanes } \\
\hline 5 & 240 & 0.57 & 1,2,4-Trimethylcyclopentane & $930-57-4$ & 780 & 779 & - \\
\hline 8 & 252 & 0.58 & 1,4-Dimethylcyclohexane & $589-90-2$ & 800 & - & 806 \\
\hline 25 & 534 & 0.60 & Propylcyclohexane & 2040-95-1 & 935 & 929 & - \\
\hline 34 & 576 & 0.59 & 1,1,2,3-Tetramethylcyclohexane & $6783-92-2$ & 953 & 958 & - \\
\hline 47 & 618 & 0.60 & 2-Ethyl-1,3-dimethylcyclohexane & $7045-67-2$ & 978 & - & - \\
\hline 48 & 624 & 0.59 & 1-Methyl-3-propylcyclohexane & $4291-80-9$ & 982 & - & - \\
\hline
\end{tabular}


Table 2 (Continued)

\begin{tabular}{|c|c|c|c|c|c|c|c|}
\hline Peak number & ${ }^{1} t_{\mathrm{R}}^{\mathrm{a}}(\mathrm{s})$ & ${ }^{2} t_{\mathrm{R}}{ }^{\mathrm{a}}(\mathrm{s})$ & Compounds & CAS number & $\mathrm{RI}_{\text {calc }}{ }^{\mathrm{b}}$ & $\mathrm{RI}_{\text {lit. }}{ }^{\mathrm{c}}(\mathrm{GC})$ & $\mathrm{RI}_{\text {lit. }}{ }^{\mathrm{d}}(\mathrm{GC} \times \mathrm{GC})$ \\
\hline 49 & 630 & 0.58 & 1-Methyl-3-(2-methylpropyl)cyclopentane & 29053-04-1 & 985 & - & - \\
\hline 53 & 642 & 0.59 & Ethylpropylcyclopentane & $54111-97-6$ & 991 & - & - \\
\hline 57 & 654 & 0.59 & 1-Methyl-2-propylcyclohexane & 4291-79-6 & 997 & - & - \\
\hline 63 & 732 & 0.57 & Hexylcyclopentane & $1003-19-6$ & 1047 & - & - \\
\hline 73 & 792 & 0.57 & 1,4-Dimethylcycloctane & $13151-98-9$ & 1085 & - & - \\
\hline 77 & 804 & 0.59 & 1-Ethyl-2-propycylohexane & $62238-33-9$ & 1093 & - & - \\
\hline 105 & 996 & 0.62 & Hexylcyclohexane & 4292-75-5 & 1236 & 1237 & - \\
\hline 116 & 1068 & 0.65 & 1-Hexyl-3-methylcyclohexane & $591-48-0$ & 1296 & - & - \\
\hline 118 & 1080 & 0.60 & 1-Butyl-2-propylcyclopentane & $62199-50-2$ & 1306 & - & - \\
\hline \multicolumn{8}{|c|}{ - } \\
\hline \multicolumn{8}{|l|}{ Linear } \\
\hline 10 & 252 & 0.60 & 3-Octene & 592-98-3 & 803 & 800 & - \\
\hline 14 & 330 & 0.61 & 2,4-Dimethyl-1-heptene & $19549-87-2$ & 836 & 842 & - \\
\hline 17 & 450 & 0.61 & 1-Nonene & 124-11-8 & 892 & 889 & - \\
\hline 27 & 546 & 0.57 & Alkene isomer $(m / z 55,41,69)$ & - & 941 & - & - \\
\hline 29 & 552 & 0.57 & 3-Methyl-1-nonene & 2980-41-4 & 944 & 944 & - \\
\hline 32 & 570 & 0.59 & 3,4-Diethyl-2-hexene & $19550-82-4$ & 957 & - & - \\
\hline 37 & 582 & 0.59 & Alkene isomer $(m / z 69,41,56)$ & - & 960 & - & - \\
\hline 44 & 606 & 0.59 & Alkene isomer $(m / z 69,41,56)$ & - & 972 & - & - \\
\hline 46 & 612 & 059 & 7-Methyl-1-nonene & 2980-71-4 & 975 & 960 & - \\
\hline 56 & 648 & 0.59 & 4-Decene & 19398-89-1 & 994 & - & 994 \\
\hline 65 & 762 & 0.55 & Alkene isomer $(m / z 55,69,41)$ & - & 1066 & - & - \\
\hline 67 & 768 & 0.56 & Alkene isomer $(m / z 55,69,41)$ & - & 1070 & - & - \\
\hline 70 & 780 & 0.56 & $(Z)$-2-Decene & $20348-51-0$ & 1077 & 1072 & - \\
\hline 75 & 798 & 0.56 & Alkene isomer $(m / z 55,69,41)$ & - & 1089 & - & - \\
\hline 79 & 810 & 0.55 & Alkene isomer $(m / z 69,55,41)$ & - & 1097 & - & - \\
\hline 83 & 828 & 0.57 & Alkene isomer $(m / z 55,69,41)$ & - & 1109 & - & - \\
\hline 85 & 870 & 0.59 & 2-Methyl-1-undecene & $18516-37-5$ & 1140 & 1144 & - \\
\hline 92 & 918 & 0.60 & (E)-5-Methyl-4-undecene & 41851-94-9 & 1174 & - & - \\
\hline 93 & 924 & 0.60 & (Z)-5-Methyl-5-undecene & $57024-93-8$ & 1179 & - & - \\
\hline 94 & 942 & 0.60 & 1-Dodecene & $112-41-4$ & 1192 & 1192 & - \\
\hline 97 & 960 & 0.62 & Alkene isomer $(m / z 55,69,41)$ & - & 1206 & - & - \\
\hline 102 & 978 & 0.59 & Alkene isomer $(m / z 55,69,43)$ & - & 1221 & - & - \\
\hline \multirow{2}{*}{\multicolumn{8}{|c|}{ Aldehydes }} \\
\hline & & & & & & & \\
\hline \multicolumn{8}{|l|}{ Linear } \\
\hline 3 & 144 & 0.78 & Butanal & $123-72-8$ & 614 & 595 & - \\
\hline 9 & 252 & 1.17 & Hexanal & $66-25-1$ & 801 & 802 & - \\
\hline 21 & 474 & 1.22 & Heptanal & $111-71-7$ & 904 & 904 & - \\
\hline 35 & 576 & 0.92 & 2-Ethylhexanal & $123-05-7$ & 957 & - & 957 \\
\hline 59 & 666 & 1.06 & Octanal & $124-13-0$ & 1005 & 1003 & - \\
\hline 82 & 822 & 1.00 & Nonanal $^{\mathrm{e}}$ & 124-19-6 & 1105 & 1106 & - \\
\hline 88 & 900 & 1.28 & (E)-2-Nonenal & $18829-56-6$ & 1162 & 1164 & - \\
\hline 98 & 960 & 0.97 & Decanal & $112-31-2$ & 1206 & 1206 & - \\
\hline 109 & 1038 & 1.03 & Aldehyde isomer $(m / z 41,55,71)$ & - & 1266 & - & - \\
\hline 119 & 1086 & 1.02 & Undecanal & $112-44-7$ & 1311 & 1310 & - \\
\hline 129 & 1200 & 1.09 & Dodecanal & $112-54-9$ & 1412 & 1410 & - \\
\hline \multicolumn{8}{|c|}{ Aromatic aldehyde } \\
\hline 39 & 588 & 3.58 & Benzaldehyde ${ }^{e}$ & $100-52-7$ & 964 & 964 & - \\
\hline \multicolumn{8}{|l|}{ Ketones } \\
\hline 2 & 138 & 0.79 & 2-Butanone & $78-93-3$ & 601 & 602 & - \\
\hline 6 & 240 & 1.16 & 2-Hexanone & $591-78-6$ & 781 & 790 & - \\
\hline 16 & 438 & 1.19 & 3-Heptanone & $106-35-4$ & 887 & 885 & 884 \\
\hline 18 & 450 & 1.29 & Ketone isomer $(m / z 43,58,71)$ & - & 892 & - & - \\
\hline 54 & 642 & 1.10 & 3-Octanone & $106-68-3$ & 991 & 989 & - \\
\hline 55 & 642 & 1.33 & 6-Methyl-5-hepten-2-one & $110-93-0$ & 991 & 989 & - \\
\hline 78 & 804 & 1.03 & 2-Nonanone & $821-55-6$ & 1093 & 1093 & - \\
\hline 80 & 810 & 1.02 & Ketone isomer $(m / z 43,58,71)$ & - & 1097 & - & - \\
\hline \multicolumn{8}{|l|}{ Cyclic ketone } \\
\hline 19 & 450 & 2.07 & Ciclohexanone & $108-94-1$ & 893 & 895 & - \\
\hline \multicolumn{8}{|l|}{ Miscellaneous } \\
\hline 50 & 630 & 2.13 & 1-Octen-3-ol & $3391-86-4$ & 985 & 986 & - \\
\hline 62 & 720 & 1.78 & 2-Ethyl-1-hexanol & $104-46-7$ & 1040 & 1026 & - \\
\hline 69 & 774 & 0.99 & 2-Nonen-1-ol & $22104-79-6$ & 1074 & 1105 & - \\
\hline 71 & 780 & 1.86 & 1-Octanol & 111-87-5 & 1078 & 1068 & - \\
\hline 91 & 912 & 0.97 & 2-Decen-1-ol & 22104-80-9 & 1170 & - & - \\
\hline 51 & 630 & 3.78 & Aniline & $62-53-3$ & 986 & 971 & - \\
\hline 41 & 594 & 1.83 & Dimethyl trisulfide & $58-80-8$ & 967 & 972 & - \\
\hline 103 & 978 & 3.73 & Benzothiazole & $95-16-9$ & 1223 & 1227 & - \\
\hline
\end{tabular}

${ }^{\text {a }}$ Retention times in seconds ( $\mathrm{s}$ ) for first $\left({ }^{1} t_{\mathrm{R}}\right)$ and second $\left({ }^{2} t_{\mathrm{R}}\right)$ dimensions.

b RI: retention index obtained through the modulated chromatogram.

c RI: retention index reported in the literature for one dimensional GC with a 5\%-Phenyl-methylpolysiloxane GC column or equivalent [17-19,21-46,48-52].

d RI: retention index reported in the literature for a comprehensive GC $\times$ GC system with Equity-5 for the first dimension [20,47].

e Set of 23 metabolites previously reported in a study related to allergic asthma [3] that was used in Fig. 4.

f Information not available. 
classification rate and $Q^{2}$ were estimated by cross-validation (7 blocks splits). Model robustness was assessed using MCCV with 1000 iterations. For each of the 1000 randomly generated classification models, the number of latent variables (LV), the $Q^{2}$ (expressing the cross-validated explained variability), and the confusion matrix was computed. The selection of model complexity was based on the most frequent list of model properties that maximizes the predictive power (i.e., lower LV and higher $Q^{2}$ ). The sensitivity and the specificity of the model were then depicted from the confusion matrix resulting into a ROC map to further assess the results significance. Then, the same procedure was applied using permuted class membership. Sensitivity is calculated from the ratio between true positives (allergic asthma samples correctly predicted) and the total number of modelled breath samples, whereas specificity is determined from the ratio between true negatives (control samples correctly predicted) and the total number of modelled control GC $\times$ GC data.

\section{Results and discussion}

A previous study [3] reported the development of an HSSPME/GC-qMS methodology, as well as the optimization of important breath sampling parameters and its application to a group of children with allergic asthma and controls. To increase the information obtained on exhaled breath, in the present study the HS-SPME technique was applied to exhaled breath of a different population $(n=59)$ using a powerful tool such as the GC $\times$ GC-ToFMS, that is more sensitive, has higher chromatographic resolution and a structured chromatogram is obtained, three relevant advantages relatively to $1 \mathrm{D}-\mathrm{GC}$ analysis.

\subsection{Structured chromatogram and sensitivity}

$\mathrm{GC} \times \mathrm{GC}$ has proven to be a powerful technique in the analysis of complex samples and to detect trace components [55,56]. Automated processing of HS-SPME/GC $\times$ GC-ToFMS data was used to tentatively identify all peaks in the $\mathrm{GC} \times \mathrm{GC}$ chromatogram contour plots with signal-to-noise threshold $>80$. The peak finding routine based on deconvolution method allowed to identify ca. 350 compounds per sample comprising several chemical families: linear and ramified alkanes, cycloalkanes, alkenes, aldehydes, ketones, aromatic compounds, terpenoids and esters. From these, 134 compounds belonging to linear, ramified and cycloalkanes, alkenes, aldehydes, ketones and a group of miscellaneous compounds, were selected for further studies. The remaining compounds were considered as possible contaminants, as for example, aromatic compounds from environmental cumulative exposure [57], whereas terpenoids and esters can have its origin in ingested foods [58]. Otherwise, the linear, ramified and cycloalkanes, alkenes, aldehydes and ketones have been reported to be associated to several biochemical processes that may occur in humans [59].

The total number of compounds detected in allergic asthma exhaled breath substantially increased with the use of the GC $\times$ GC-ToFMS, approximately 8 times, when compared to the obtained results by 1D-GC-qMS [3]. By 1D-GC-qMS a total of 44 compounds were identified whereas by GC $\times$ GC-ToFMS ca. 350 compounds were tentatively identified. For example, considering the alkanes, alkenes, aldehydes and ketones, the number of detected compounds increased by $66 \%, 96 \%, 67 \%$ and $56 \%$, respectively.

The compounds included in the selected dataset were tentatively identified based on comparison of their mass spectra to home-made and commercial databases (MS), and by comparison of the RIs calculated $\left(\mathrm{RI}_{\text {calc }}\right)$ with the values reported in the literature $\left(\mathrm{RI}_{\text {lit }}\right)$ for $5 \%$ phenylpolysilphenylene-siloxane (or equivalent)

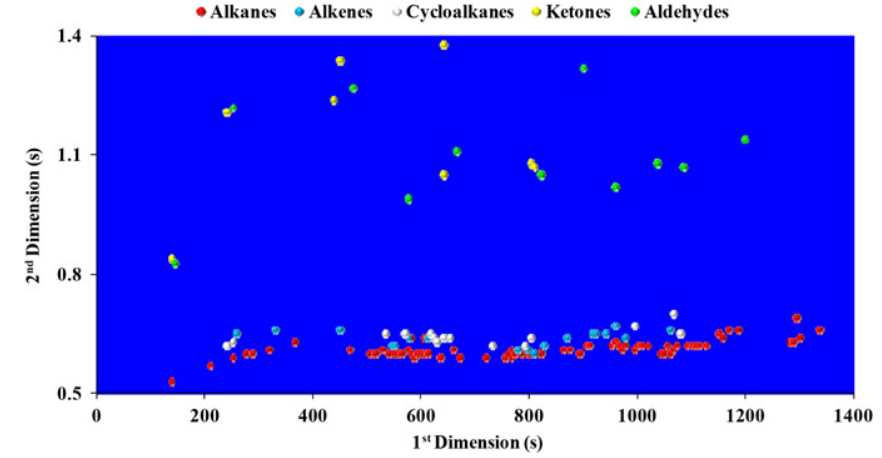

Fig. 1. Peak apex plot of the alkanes (linear, ramified and cyclic), alkenes, aldehydes and ketones identified using allergic asthma exhaled breath sample.

column (Table 2). A range between 1 and 30 was obtained for $\mathrm{RI}_{\mathrm{cal}}$ compared to the $\mathrm{RI}_{\text {lit }}$ reported in the literature $\left(\left|\mathrm{RI}_{\text {calc }}-\mathrm{RI}_{\text {lit }}\right|\right)$ for 1D-GC with 5\%-phenyl-methylpolysiloxane GC column or equivalent. This difference in RI is considered minimal (on average lower than $0.5 \%$ ), and is well justified if one takes into account that: (i) the literature data is obtained from a large range of GC stationary phases (several commercial GC columns are composed of 5\% phenylpolysilphenylene-siloxane or equivalent stationary phases), and (ii) the literature values were determined in a 1D-GC separation system, and the modulation causes some inaccuracy in first dimension retention time [56].

The most reliable way to confirm the identification of each compound is based on authentic standard co-injection, which in several cases is economically prohibitive, and often unachievable in the time available for analysis [60], or are not commercially available. Thus, GC $\times$ GC is an ideal technique for the analysis of complex mixtures where compounds of similar chemical structure are grouped into distinct patterns in the 2D chromatographic plane providing useful information on both their boiling point and polarity (if NP/P set of columns was used), and relationships of structured retentions have proved especially useful for compound identification [61]. To demonstrate the structured chromatogram a chromatographic space with higher peak density, ranging between ${ }^{2} t_{R} 0.45$ and $1.45 \mathrm{~s}$, was chosen, and a peak apex plot was depicted regarding the alkanes, alkenes, aldehydes and ketones to better visualise the attained structured chromatogram (Fig. 1). The components of each chemical group were dispersed through the peak apex plot according to their volatility $\left({ }^{1} \mathrm{D}\right)$ and polarity $\left({ }^{2} \mathrm{D}\right)$ obtained by a combination of NP/P columns. For the selected chemical families, as expected, it was observed that the decrease in volatility (high ${ }^{1} t_{R}$ ) is mainly related to the increase in the number of carbons. The structured 2D chromatographic profile was observed within each chemical family based on the properties and positions of their functional groups. Globally, based on the functional group of the chemical families under study, the ${ }^{2} t_{R}$ values increase as follows: alkanes < alkenes $\sim$ cycloalkanes $<$ ketones $\sim$ aldehydes. This information can be also confirmed in Table 2. Alkanes have the lowest polarity $\left({ }^{2} t_{R} \cong 0.48-0.64 \mathrm{~s}\right)$, followed by alkenes $\left({ }^{2} t_{R} \cong 0.57-0.62 \mathrm{~s}\right)$, cycloalkanes $\left({ }^{2} t_{R} \cong 0.57-0.65 \mathrm{~s}\right)$, ketones $\left({ }^{2} t_{R} \cong 0.79-1.33 \mathrm{~s}\right)$, and aldehydes $\left({ }^{2} t_{R} \cong 0.78-3.58 \mathrm{~s}\right)$. This information is especially useful for classifying unidentified compounds.

A further advantage of a comprehensive chromatographic system can be verified, as compounds with similar boiling points that could co-elute in a 1D system, as for example 4-ethyloctane (33), 1,1,2,3-tetramethylcyclohexane (34) and 2-ethylhexanal (35) [3], are able to be separated using the comprehensive chromatographic system (Fig. 2). These compounds have similar volatility, the same ${ }^{1} t_{R}$ of $576 \mathrm{~s}$ but present different polarities, and as a consequence 


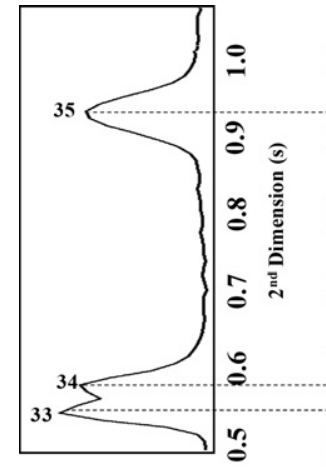

${ }^{1} \mathrm{D} t_{R}-576 \mathrm{~s}$

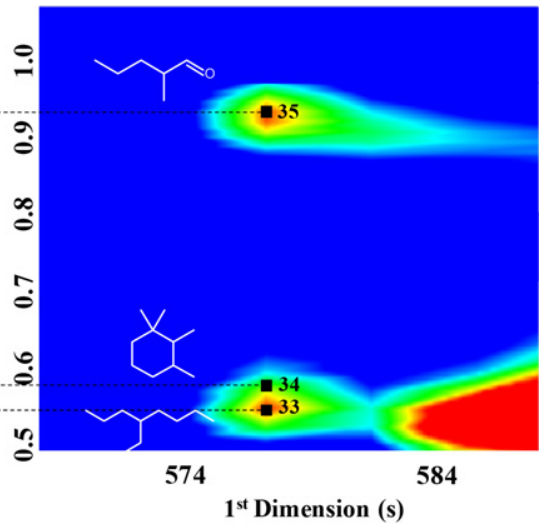

$1^{\text {st }}$ Dimension (s)
Fig. 2. Blow-up of a part of total ion $\mathrm{GC} \times \mathrm{GC}$ chromatogram contour plot obtained from an allergic asthma exhaled breath showing the corresponding ramified alkane, cycloalkane and ramified aldehyde: 4-ethyloctane (33), 1,1,2,3tetramethylcyclohexane (34) and 2-ethylhexanal (35), respectively.

they were separated by the second column $\left({ }^{2} t_{R}\right.$ of $0.56,0.59$ and $0.92 \mathrm{~s}$, respectively).

Different concentrations, ranging from nmolar to $\mu$ molar have been reported for volatile breath components [13,62], so an important issue is the sensitivity of the used equipment. Consequently, the GC $\times$ GC-ToFMS sensitivity was verified, and for this purpose a standard solution comprising standards pertaining to the previously selected families (alkanes, alkenes, aldehydes and ketones) was used, whose concentration, for instance, varied between $20 \mathrm{pg} / \mathrm{L}$ to $200 \mathrm{ng} / \mathrm{L}$. The standards from the tested compound families were detected at the level under study (data not shown). For demonstration purposes, 1-dodecene (94) and dodecane (95), showed in Fig. 3, were detected at pg/L and ng/L levels. The studied range was lower than the reported values to verify that this equipment is able to detect compounds at this concentration level, which could be relevant to identify target compounds that could be important for asthma metabolomic studies.

\subsection{Multivariate analysis in the establishment of asthma "breath-print"}

In the previous study [3], 28 compounds, from a total of 44 , were selected and distinction was achieved with two relatively defined clusters between the control and the allergic asthma groups. As a first approach, using a different allergic asthma and control children population, from the 28 compounds identified by GC-qMS [3], 23 were also identified by GC $\times$ GC-ToFMS and selected for multivariate analysis (indicated in Table 2 ) to verify the results obtained in the previous study. PLS-DA was applied to the GC $\times$ GC chromatographic unit variance scaled areas to establish a preliminary classification model and assess the relationships between the compounds and the samples under study. Fig. 4A shows that there are two defined clusters with the control group being mainly associated to LV1 negative values and the allergic asthma group to LV1 positive values. From the previous study [3], the allergic asthma group was mainly characterized by decane, dodecane and tetradecane, which were confirmed with this new set of children (Fig. 4B).

However a clear distinction was sought, thus PLS-DA was applied to the full dataset of 134 metabolites identified by GC $\times$ GC-ToFMS. The results obtained are shown in Fig. 5A that presents the scores scatter plot of the first two Latent Variables (LV1 × LV2), while Fig. 5B (corresponding LV1 loading weights plot) establishes the contribution of each volatile metabolite that promotes the observed distinction. According to MCCV statistics, the PLS-DA model had a classification rate of $98 \%$ and showed $96 \%$ sensitivity ( $\cong 4 \%$ allergic asthma children being misclassified as controls) and $95 \%$ specificity ( $\cong 5 \%$ of false positives). The most frequent $Q^{2}$ value was around 0.9 (Fig. 6), with a large prevalence of values in the range of $0.8-1$. These results suggest that confounding factors, such as, ambient air, gender or age seems to have no significance in the distinction power.

Scores scatter plot (Fig. 5A) shows that the control group is associated to LV1 negative values whereas the allergic asthma group is linked to positive LV1 values. As observed in Fig. 5B, nonane, 2,2,4,6,6-pentamethylheptane, decane, 3,6-dimethyldecane, dodecane, and tetradecane are related to the allergic asthma group. The control group is mainly characterized by 6-methyl-5-hepten2-one, 1-dodecene, nonanal, decanal, and dodecanal. Comparing these results to the previous study [3], there was an increase in the number of compounds that characterize allergic asthma and control samples. Interestingly the controls are characterized mainly by aldehydes and the asthmatic children are characterized by alkanes, namely those that arise from the corresponding aldehydes. Hence a pattern seems to be noticeable that mainly involves these two chemical families. The behaviour shown in the control group has also been reported by Corradi et al. [63] as nonanal had lower
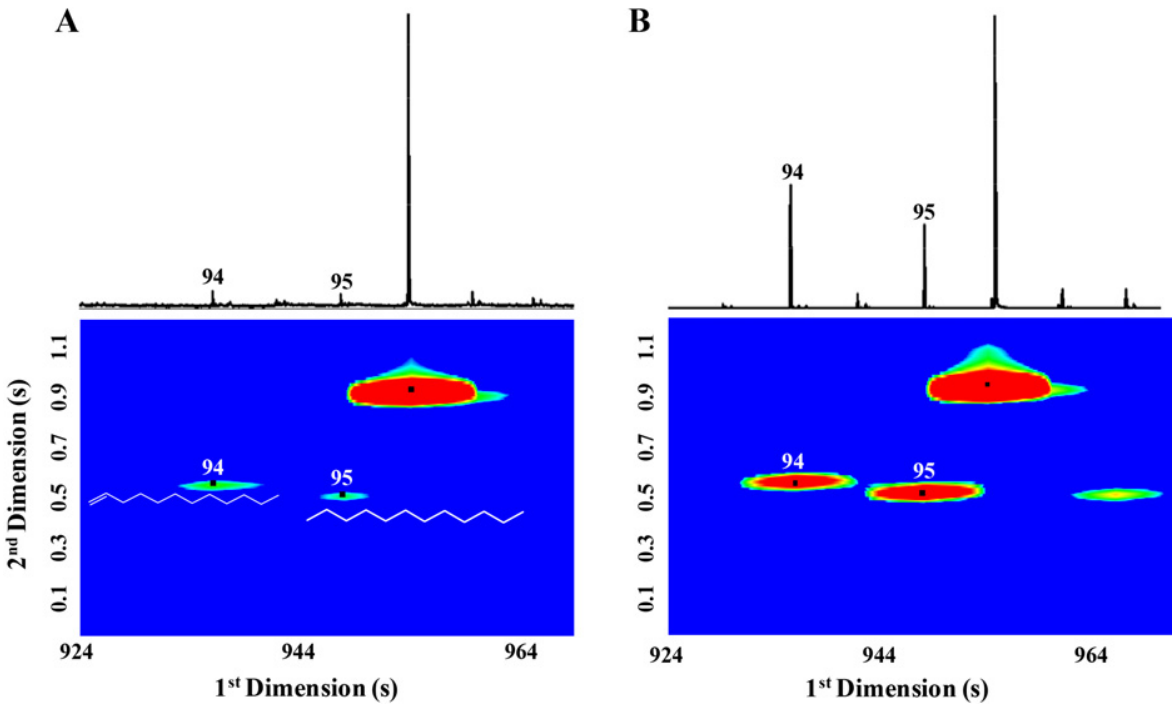

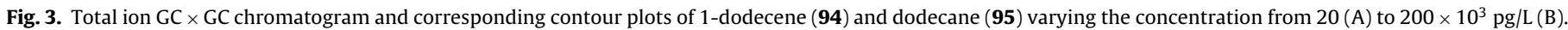



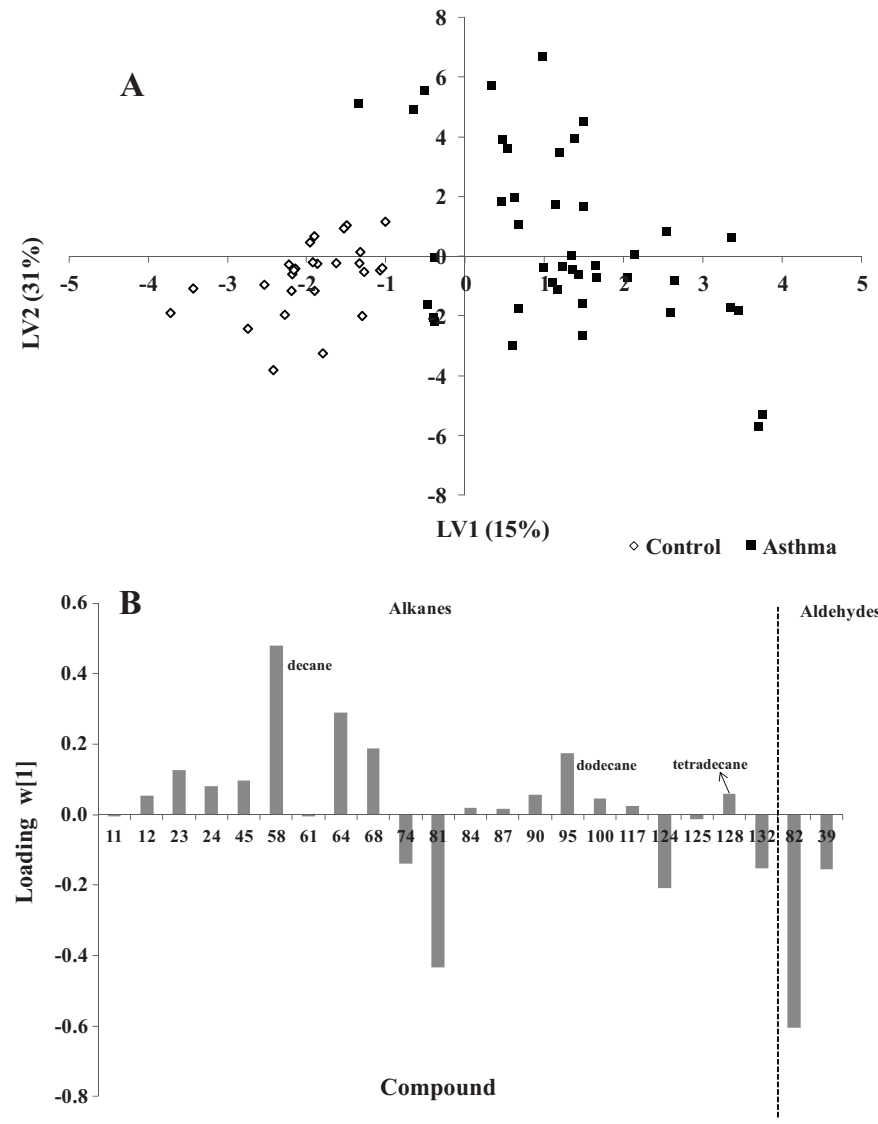

Fig. 4. PLS-DA LV $1 \times$ LV2 scores scatter plot $(A)$ and LV1 loading weights plot (B) of exhaled breath for allergic asthma and control children using a sub-set of 23 metabolites identified by GC $\times$ GC-ToFMS, and previously reported in a study related to allergic asthma [7] (peak attribution shown in Table 2).

values in exhaled breath condensate of children with exacerbated asthma (before and after treatment) when compared to control. The behaviour of the remaining aldehydes compounds that have higher weight in the control group has not been previously described.

A relevant aspect brought by the results is that from the 67 identified alkanes 19 are methylated, which corresponds to $28 \%$ of this chemical family and from these, two methylated compounds, as for example 2,2,4,6,6-pentamethylheptane and 3,6-dimethyldecane have a major contribution in the observed distinction. The methylated alkanes family have also been previously reported as these may well be important in asthma characterization $[2,64]$. These compounds also have an important role in diseases, in which oxidative stress apparently may be involved, but to other extents, and with different consequences than asthma, such as lung and breast cancer, as well as in lung cancer cell lines [65-67]. These compounds have been reported in literature in other exhaled breath studies associated to pathological states of the lungs, but as individual markers. For example, 2,2,4,6,6-pentamethylheptane and decane were identified and compared by Poli et al. [68] in exhaled breath of patients with non-small lung cancer (NSLC), chronic obstructive pulmonary disease (COPD), smokers and controls and their concentrations were higher for NSLC, COPD and smokers when compared to controls. Dodecane has been proposed as lung cancer markers [69,70].

These results evidence that overall, for the allergic asthma group, there is a greater weight of the alkanes confirming the previous study [3] whereas aldehydes have a major importance in the characterization of the control group. Alkanes, in the sequence of oxidation reactions, are end-compounds that have been associated to oxidative stress and inflammation processes [71] and the hypothesis formed is that these compounds indicate that the oxidative state is at a higher extent in asthmatics when compared to controls leading to the obtained differences and consequently the alkanes can be associated to allergic asthma. These particular compounds can be formed in the inflammatory response induced by the immune system that leads to the production of activated leukocytes causing the cells to uptake oxygen releasing reactive oxygen species which can damage lung tissue contributing to elevated oxidative stress in asthma [72] and there is evidence that alkanes can arise as products of lipid peroxidation of unsaturated fats [73]. Lipid metabolism and oxidative metabolism in the mitochondria have been reported recently to be altered in urine of asthma patients [74] and a conjecture could be made that this alteration shown in urine can also be noticed in exhaled breath, considering the alkanes as a measurement of lipid and oxidative metabolism that characterize the allergic asthma group.

\section{3. "Breath-print" exploration as a potential aid to the clinical} practice

Therapy monitoring is one of the challenges of actual medicine as patients may or may not follow treatment as prescribed by the physician. To test the hypothesis that a change would occur in the exhaled breath composition with the intake of the prescribed medication, a naive patient (patient that had never taken an asthma drug) was recruited. This naive patient was diagnosed by physician as having allergic asthma, and exhaled breath was collected previous medication intake and three other moments after intake. The medication that was prescribed was the combination of anti-histamine and a leukotriene receptor antagonist. Anti-histamines are drugs that inhibit the action of histamine whereas leukotriene receptor antagonist inhibits leukotrienes that are compounds produced by the immune system that cause inflammation. This therapy combination directed to block the effects of histamine and leukotriene mediators was performed as it is shown that it is better than standalone therapy [75]. The behaviour of a naive child was monitored throughout 24 days (Fig. $5 \mathrm{~A}$, marked by the path trajectory). Initially and after 18 days after the intake of the prescribed drugs, the naive individual remains in LV1 positive values but far from the remaining controlled subjects. There is an evolution throughout LV1 axis with treatment administration explained by the area reduction of nonane, 2,2,4,6,6-pentamethylheptane, decane, 3,6dimethyldecane, and tetradecane. Considering that asthma crisis is mainly characterized by inflammation, which is accompanied by oxidative stress and subsequently lipid peroxidation, and that alkanes are evidence of these biochemical processes, the observed decrease may be due to a lesser inflammation state of this subject leading to lower areas of these compounds. Clinically, the child in the initial stages was in a crisis situation almost in a daily basis and throughout the 24 days there was a significant improvement of the asthma status control.

As verified, the obtained "breath-print" allowed the distinction between allergic asthmatic and control children which could be helpful in understanding this pathology through a better insight into the metabolic pathways that may be associated to this condition. Nevertheless, for clinical purposes, and having in mind the future of molecular diagnosis, a smaller set of compounds is necessary to allow a rapid use of exhaled breath for complementary purposes in diagnosis, to follow the disease status and/or the medication effect. For this intent, and taking into consideration the previous assertion that a pattern of alkanes and aldehydes clearly defines both populations under study, just 9 compounds (nonane, 2,2,4,6,6-pentamethylheptane, decane, 3,6-dimethyldecane, dodecane, tetradecane, nonanal, decanal, and dodecanal) were selected 

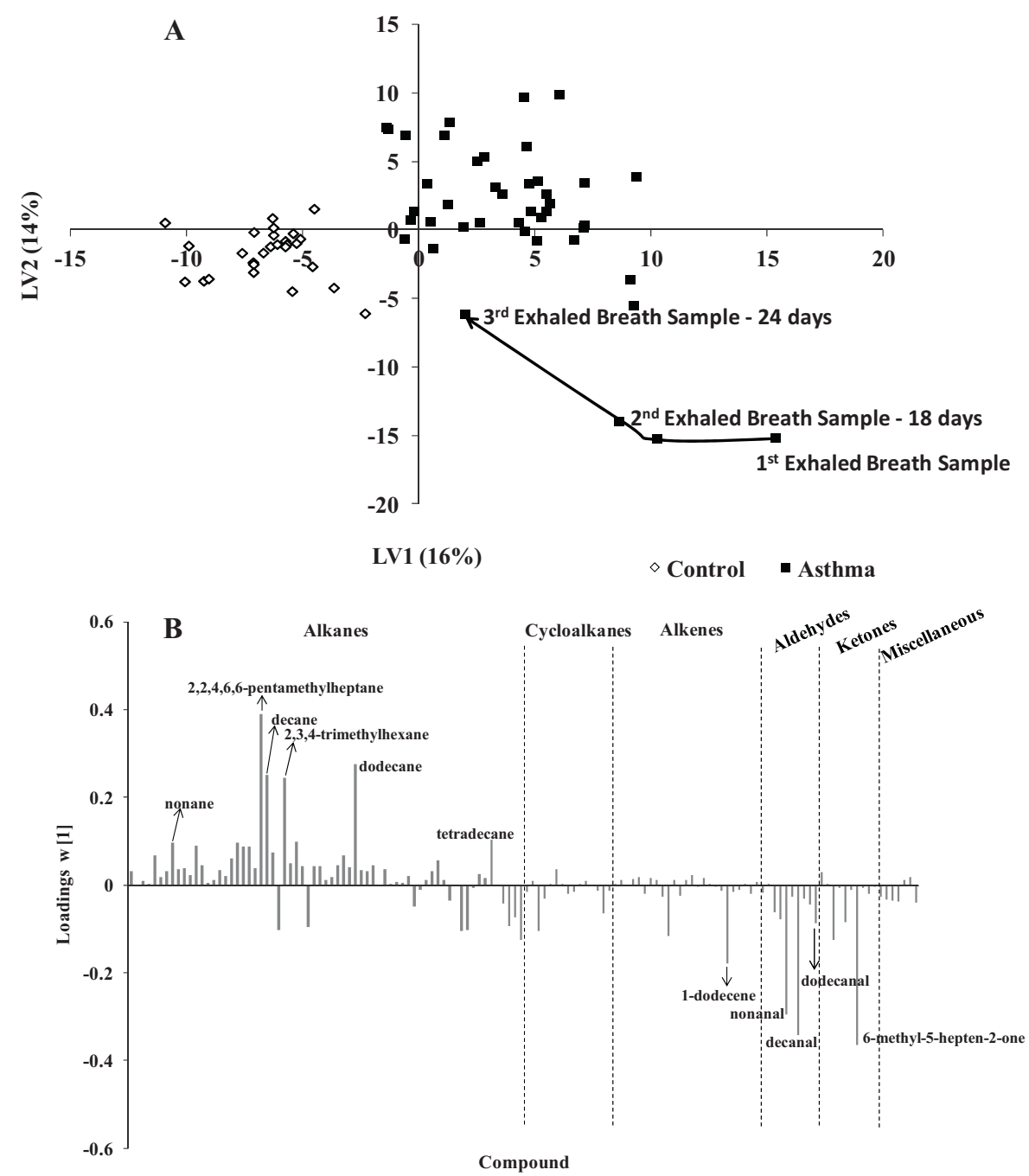

Fig. 5. PLS-DA LV1 $\times$ LV2 scores scatter plot (A) and LV1 loading weights plot (B) of exhaled breath for allergic asthma and control children using dataset of 134 metabolites identified by GC $\times$ GC-ToFMS.

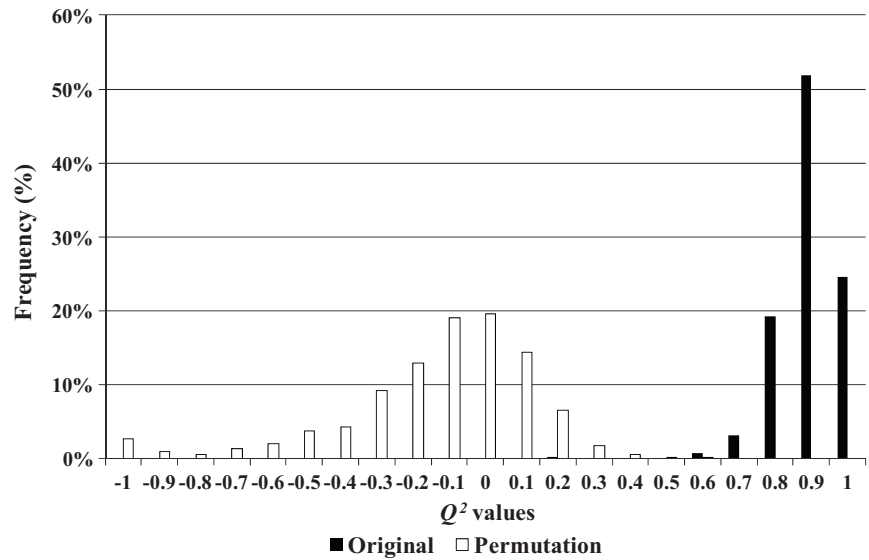

Fig. 6. $Q^{2}$ values distribution of the original and permuted Monte-Carlo Cross Validation for PLS-DA of exhaled breath of full dataset (134 metabolites). for a new PLS-DA model. The results are shown in Fig. 7A and the chosen pattern was able to discriminate both groups showing the exhaled breath testing is a tool that can be used as non-invasive diagnostic method for allergic asthma. To assess both the predictive power and classification model robustness, MCCV was also performed, using similar conditions to the previous test. According to MCCV statistics, the PLS-DA model had a classification rate of $96 \%$ and showed $98 \%$ sensitivity ( $\cong 2 \%$ allergic asthma children being misclassified as controls) and $93 \%$ specificity ( $\cong 7 \%$ of false positives). The most frequent $Q^{2}$ value was around 0.8 (Fig. 8), with a large prevalence of values in the range of $0.7-0.9$. Classification rate and specificity were slightly lower than those obtain for the full dataset, but, still, remained high. The sensitivity was improved. These results suggest that the model is robust, even using this set of 9 metabolites, reducing the time of data processing, and thus, becoming more expedite method for the clinical purposes.

A remarkable result observed in Fig. 7 is shown by the path of the naive child (a through $\mathrm{d}$ - four breath sampling), which suggest the mitigation of asthma symptoms following drug intake. 

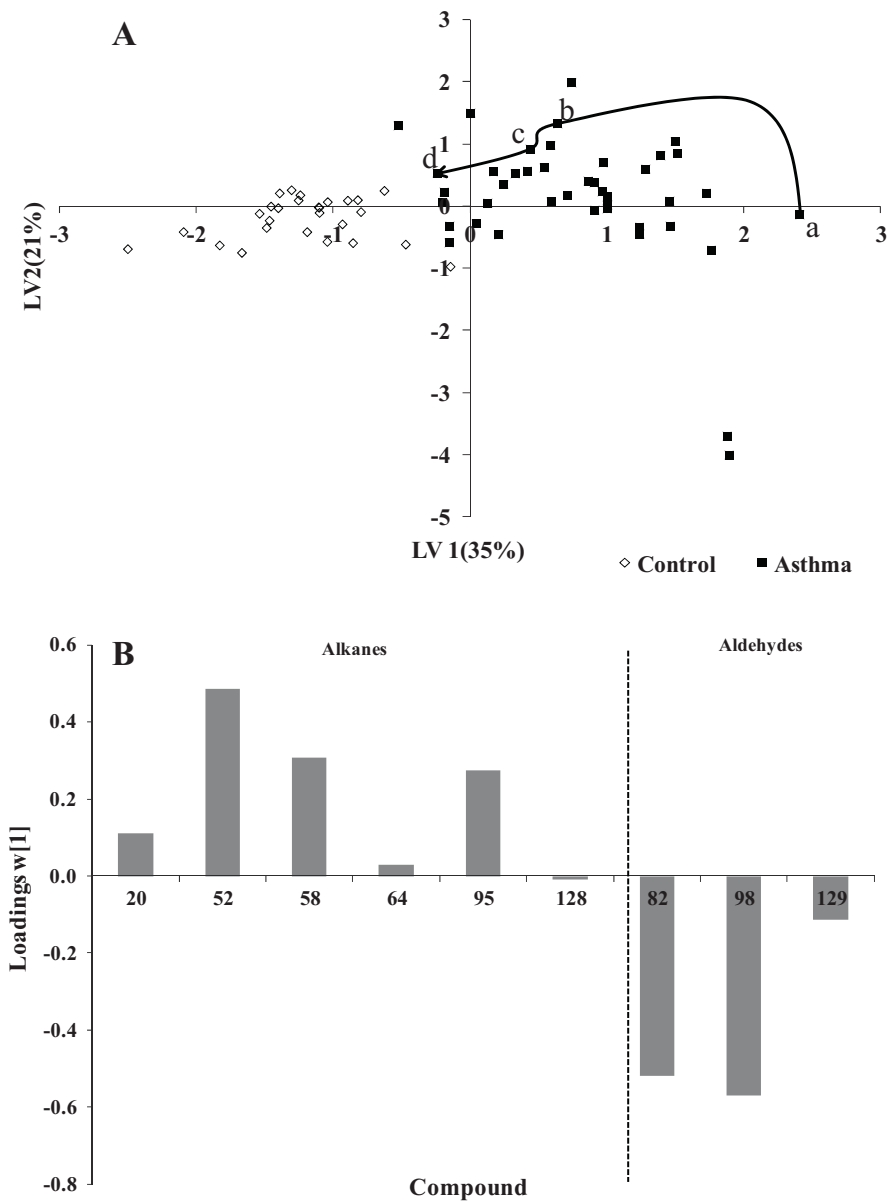

Fig. 7. PLS-DA LV $1 \times$ LV2 scores scatter plot (A) and LV1 loading weights plot (B) of exhaled breath for allergic asthma and control children using a sub-set of 9 compounds: nonane (20), 2,2,4,6,6-pentamethylheptane (52), decane (58), 3,6dimethyldecane (64), dodecane (95), tetradecane (128), nonanal (82), decanal (98), dodecanal (129). Path of the naive child - a through $\mathrm{d}-$ four breath sampling.

This suggests the application of exhaled breath analysis, not only for metabolomic profiling of allergic asthma, but also in clinical practice as a possible surrogate to the invasive diagnosis tests performed actually.

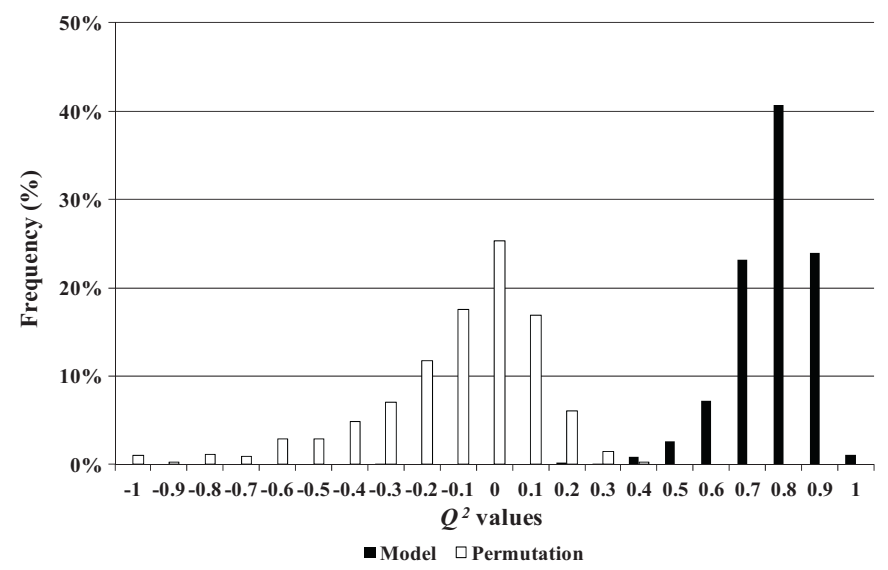

Fig. 8. $Q^{2}$ values distribution of the original and permuted Monte-Carlo Cross Validation for PLS-DA of exhaled breath of sub-set of 9 metabolites: nonane, 2,2,4,6,6-pentamethylheptane, decane, 3,6-dimethyldecane, dodecane, tetradecane, nonanal, decanal, and dodecanal.

\section{Conclusions}

In this study, the development of the first HS-SPME/GC $\times$ GC-ToFMS methodology was reported for the analysis of exhaled breath of allergic asthma children and the advantages of comprehensive chromatography was explored in issues such as the structured chromatogram and sensitivity. The structured 2D chromatogram that arose from ${ }^{1} \mathrm{D}$ volatility and ${ }^{2} \mathrm{D}$ polarity was shown and sensitivity was assessed. A well-defined chromatographic space was obtained with the resulting structured chromatogram, which can aid posterior exhaled breath analysis for example in the identification of otherwise unknown compounds. Subsequently, the potentiality of the GC $\times$ GC-ToFMS was verified in exhaled breath samples from allergic asthma and control children.

The methodology allowed the identification of several hundred compounds pertaining to different chemical families (linear and ramified alkanes, cycloalkanes, alkenes, aldehydes, ketones, aromatic compounds, terpenoids and esters). Multivariate analysis was performed by PLS-DA to a group of selected compounds pertaining to alkanes, alkenes, aldehydes, and ketones and the GC $\times$ GC-ToFMS showed to be advantageous as distinction between both groups was attained and a high classification rate was achieved. The obtained "breath-print" allowed the discrimination between allergic asthmatic and control children, providing insights into the metabolic pathways that may be associated to allergic asthma. In general, a pattern of six compounds pertaining to the alkanes characterized the asthmatic population: 3,6dimethyldecane, nonane, 2,2,4,6,6-pentamethylheptane, decane, dodecane, and tetradecane. Otherwise, a set of aldehydes (nonanal, decanal, and dodecanal) characterizes the control population. Thus, a smaller set of 9 compounds comprising alkanes and aldehydes was chosen to verify the potential clinical usefulness of exhaled breath for allergic asthma evaluation and the obtained results are very satisfactory as, with this set, distinction was obtained. It was also confirmed that it is also possible to follow through the effects of medication.

Exhaled breath metabolome presents itself as a challenge, and in our opinion, GC $\times$ GC-ToFMS offers advantages that were verified in the present study that corresponded to the challenge. This new methodological approach to characterize allergic asthma as a function of its metabolomic patterns will enhance the possibility of further allergic asthma pathways knowledge. It also provides with an easier methodology combined with a non-invasive sampling for allergic respiratory disease assessment, regarding diagnostic, prognostic and treatment follow-up. Further studies with a larger population are necessary to confirm these findings.

\section{Acknowledgements}

M. Caldeira thanks FCT (Fundação para a Ciência e Tecnologia) for his Ph.D. grant (SFRH/BD/40374/2007). The authors are grateful to the donors that kindly supplied the samples and to Paediatric and Immunoalergology Services of the Hospital Infante D. Pedro E.P.E (Aveiro, Portugal) for allergic asthma samples, as well as, CIAQ (Centro de Infância de Arte e Qualidade, Aveiro, Portugal) for control samples. The financial support of the Research Unit 62/94, QOPNA (Project PEst-C/QUI/UI0062/2011) and the conditions to perform this study are also acknowledged. The authors also thank Sigma - Aldrich (Portugal) for providing the first dimension column for GC $\times$ GC-ToFMS analysis.

\section{References}

[1] Global Strategy for Asthma Management and Prevention. National Institutes of Health, National Heart, Lung and Blood Institute, Bethesda. www.ginasthma.org (last updated 2010) (last accessed 27.02.11). 
[2] J.W. Dallinga, C.M. Robroeks, J.J.B.N. Van Berkel, E.J.C. Moonen, R.W.L. Godschalk, Q. Jobsis, E. Dompeling, E.F.M. Wouters, F.J. Van Schooten, Clin. Exp. Allergy 40 (2009) 68.

[3] M. Caldeira, A.S. Barros, M.J. Bilelo, A. Parada, J.S. Câmara, S.M. Rocha, J. Chromatogr. A 1218 (2011) 3771.

[4] M. Barker, M. Hengst, J. Schmid, H.-J. Buers, B. Mittermaier, D. Klemp, R. Koppmann, Eur. Respir. J. 27 (2006) 929.

[5] I. Horváth, Z. Lázár, N. Gyulai, M. Kollai,.G. Losonczy, Eur. Respir. J. 34 (2009) 261.

[6] E.M. Gaspar, A.F. Lucena, J.D. da Costa, H.C. das Neves, J. Chromatogr. A 1216 (2009) 2749.

[7] T. Górecki, O. Panić, N. Oldridge, J. Liq. Chromatogr. Relat. Technol. 29 (2006) 1077.

[8] P. Marriott, R. Shellie, Trend. Anal. Chem. 21 (2002) 573.

[9] R. Shellie, P.J. Marriott, P. Morrison, Anal. Chem. 73 (2001) 1336.

[10] M. Libardoni, P.T. Stevens, J.H. Waite, R. Sacks, J. Chromatogr. B 842 (2006) 13.

[11] J.M. Sanchez, R.D. Sacks, Anal. Chem. 78 (2006) 3046.

[12] M. Mieth, J.K. Schubert, T. Groger, B. Sabel, S. Kischel, P. Fuchs, D. Hein, R. Zimmermann, W. Miekisch, Anal. Chem. 82 (2010) 2541.

[13] N. Marczin, S.A. Kharitonov, M.H. Yacoub, P.J. Barnes, Disease Markers in Exhaled Breath, Taylor \& Francis, New York, 2005, p. 220.

[14] P. Mochalski, B. Wzorek, I. Sliwka, A. Amann, J. Chromatogr. B 877 (2009) 189.

[15] J. Dallüge, J. Beens, U.A.T. Brinkman, J. Chromatogr. A 1000 (2003) 69.

[16] L. Mondello, P.Q. Tranchida, P. Dugo, G. Dugo, Mass Spectrom. Rev. 27 (2008) 101.

[17] E. Engel, C. Baty, D. LeCorre, I. Souchon, N. Martin, J. Agric. Food Chem. 50 (2002) 6459.

[18] P. Ciccioli, E. Brancaleoni, A. Cecinato, R. Sparapani, M. Frattoni, J. Chromatogr. A 643 (1993) 55.

[19] S. Wu, H. Zorn, U. Krings, R.G. Berger, Flavour Frag. J. 22 (2007) 53.

[20] X. Xu, L.L.P. van Stee, J. Williams, J. Beens, M. Adahchour, R.J.J. Vreuls, U.A.T. Brinkman, Atmos. Chem. Phys. 3 (2003) 665.

[21] C.E. Quijano, G. Salamanca, J.A. Pino, Flavour Frag. J. 22 (2007) 401.

[22] E.A. Courtois, C.E. Paine, P.A. Blandinieres, D. Stien, J. Bessiere, E. Houel, C. Baraloto, J. Chave, J. Chem. Ecol. 35 (2009) 1349.

[23] N. Ramarathnam, L.J. Rubin, L.L. Diosady, J. Agric. Food Chem. 41 (1993) 933.

[24] N. Ramarathnam, L.J. Rubin, L.L. Diosady, J. Agric. Food Chem. 41 (1993) 939.

[25] E. Alissandrakis, A.C. Kibaris, P.A. Tarantilis, P.C. Polissiou, J. Sci. Food Agric. 85 (2005) 1444.

[26] V.G. Zaikin, R.S. Borisov, J. Anal. Chem. 57 (2002) 544.

[27] J.A. Pino, J. Mesa, Y. Muñoz, M.P. Martí, R. Marbot, J. Agric. Food Chem. 53 (2005) 2213.

[28] G. Flamini, M. Tebano, P.L. Cioni, Y. Bagci, H. Dural, K. Ertugrul, A. Savran, Plant Syst. Evol. 261 (2006) 217.

[29] Z. Wang, M. Fingas, K. Li, J. Chromatogr. Sci. 32 (1991) 367.

[30] C. Macku, T. Shibamoto, J. Agric. Food Chem. 11 (1991) 1987.

[31] X. Zhang, L. Ding, Z. Sun, L. Song, T. Sun, Chromatographia 70 (2009) 511.

[32] A. Jarunrattanasri, C. Theerakulkait, K.R. Cadwallader, J. Agric. Food Chem. 55 (2007) 3044.

[33] M. Hazzit, A. Baaliouamer, M.L. Faleiro, M.G. Miguel, J. Agric. Food Chem. 54 (2006) 6314.

[34] C.E. Rostad, W.E. Pereira, J. Hist. Res. Chromatogr. Chromatogr. Commun. 9 (1986) 328.

[35] K. Insausti, V. Goñi, E. Petri, C. Gorraiz, M.J. Beriain, Meat Sci. 70 (2005) 83.

[36] G. Flamini, L. Cioni, I. Morelli, Flavour Frag. J. 19 (2004) 327.

[37] R.B. Singer, A. Flach, S. Koehler, A.J. Marsaioli, M.C.E. Amaral, Ann. Bot. Rome 93 (2004) 755.

[38] S. Maccioni, R. Baldini, P. Cioni, M. Tebano, G. Flamini, Flavour Fragr. J. 22 (2007) 61.

[39] E. Gómez, C.A. Ledbetter, P.L. Hartsell, J. Agric. Food. Chem. 41 (1993) 1669.

[40] Y.X. Zeng, C.X. Zhao, Y.Z. Liang, H. Yang, H.Z. Fang, L.Z. Yi, Z.D. Zeng, Anal. Chim. Acta 595 (2007) 328.
[41] J.L. Berdague, C. Denoyer, J.L. Wuéré, E. Sermon, J. Agric. Food Chem. 39 (1991) 1257.

[42] W.A. Asuming, P.S. Beauchamp, J.T. Descalzo, B.C. Dev, V. Dev, S. Frost, C.W. Ma, Biochem. Syst. Ecol. 33 (2005) 17.

[43] S. Celik, R.S. Gokturk, G. Flamini, P.L. Cioni, I. Morelli, Biochem. Syst. Ecol. 33 (2005) 617.

[44] G. Flamini, M. Tebano, P.L. Cioni, Anal. Chim. Acta 589 (2007) 120.

[45] H. Widmer, J. Gas Chromatogr. 5 (1967) 506.

[46] C.E. Quijano, G. Salamanca, J.A. Pino, Flavour Fragr. J. 22 (2007) 401.

[47] M. Kallio, M. Jussila, T. Rissanen, P. Antilla, K. Hartonen, A. Reissel, R. Vreuis, M. Adahchour, T. Hyotylainen, J. Chromatogr. A 1125 (2006) 234.

[48] W.C. Lai, C. Song, Fuel 37 (1995) 1436.

[49] H. Rembold, P. Wallner, S. Nitz, H. Kollmannsberger, F. Drawert, J. Agric. Food Chem. 37 (1989) 659.

[50] E. Alissandrakis, P.A. Tarantilis, P.C. Harizanis, M. Polissiou, J. Agric. Food Chem. 55 (2007) 8152.

[51] G. Flamini, P. Cioni, I. Morelli, Food Chem. 91 (2005) 63.

[52] F. Kenig, D.J.H. Simons, D. Crich, J.P. Cowen, G.T. Ventura, T. Rehbein-Khalily, Org. Geochem. 36 (2005) 117.

[53] H. Van den Dool, P.D. Kratz, J. Chromatogr. 11 (1963) 463.

[54] L. Eriksson, E. Johansson, N. Kettaneh, N. Wold, S. Wold, Multi and Megavariate Data Analysis, Principles and Applications, Umetrics AB, Umea, Sweden, 2001.

[55] R. Perestrelo, A.S. Barros, J.S. Câmara, S.M. Rocha, J. Agric. Food Chem. 59 (2011) 3186.

[56] I. Silva, S.M. Rocha, M.A. Coimbra, J. Marriott, Chromatogr. A 1217 (2010) 5511.

[57] J.D. Pleil, M.A. Stigiel, J.R. Sobus, S. Tabucchi, A.J. Ghio, M.C. Madden, J. Chromatogr. B 878 (2010) 1753.

[58] J. Beauchamp, F. Kirsch, A. Buettner, J. Breath Res. 4 (2010) 1.

[59] W. Miekisch, J. Schubert, G. Noeldge-Schomburg, Anal. Chim. Acta 347 (2004) 25.

[60] C. von Mühlen, P.J. Marriott, Anal. Bioanal. Chem. 401 (2011) 2351.

[61] T.C. Tran, G.A. Logan, E. Grosjean, D. Ryan, P.J. Marriott, Geochim. Cosmochim. Acta $74(2010) 6468$.

[62] J. Rudnicka, T. Kowalkowski, T. Ligor, B. Buszewski, J. Chromatogr. B 879 (2011) 3360.

[63] M. Corradi, G. Folesani, R. Andreoli, P. Manini, A. Bodini, G. Piacentini, S. Carraro, S. Zanconato, E. Baraldi, Am. J. Respir. Crit. Care Med. 167 (2003) 395.

[64] B. Ibrahim, M. Basanta, P. Cadden, D. Singh, D. Douce, A. Woodcock, S.J. Fowler, Thorax 66 (2011) 804.

[65] M. Ligor, T. Ligor, A. Bajtarevic, C. Ager, M. Pienz, M. Klieber, H. Denz, M. Fiegl, W. Hilbe, W. Weiss, P. Lukas, H. Jamnig, M. Hackl, B. Buszewski, W. Miekisch, J. Schubert, A. Amann, Clin. Chem. Lab. Med. 47 (2009) 550.

[66] W. Filipiak, A. Sponring, A. Filipiak, C. Ager, J. Schubert, W. Miekisch, A. Amann, J. Troppmair, Cancer Epidemiol. Biomarkers Prev. 19 (2010) 182.

[67] A. Bajtarevic, C. Ager, M. Pienz, M. Klieber, K. Schwarz, M. Ligor, T. Ligor, W. Filipiak, H. Denz, M. Fiegl, W. Hilbe, W. Weiss, P. Lukas, H. Jamnig, M. Hackl, A. Haidenberger, B. Buszewski, W. Miekisch, J. Schubert, A. Amann, BMC Cancer 9 (2009) 348.

[68] D. Poli, P. Carbognani, M. Corradi, M. Goldoni, O. Acampa, B. Balbi, L. Bianchi, M. Rusca, A. Mutti, Respir. Res. 6 (2005) 71.

[69] X. Chen, F. Xu, Y. Wang, Y. Pan, D. Lu, P. Wang, K. Ying, E. Chen, W. Zhang, Cancer 110 (2007) 835.

[70] H. Yu, L. Xu, P. Wang, J. Chromatogr. B 826 (2005) 69.

[71] S.A. Kharitonov, P.J. Barnes, Am. J. Respir. Crit. Care Med. 163 (2001) 1693.

[72] W. MacNee, Eur. J. Pharmacol. 429 (2001) 195.

[73] E. Aghdassi, J. Allard, Free Rad. Biol. Med. 28 (2000) 880.

[74] E. Saude, C. Skappak, S. Regush, K. Cook, A. Ben-Zvi, A. Becker, R. Moqbel, B. Skyes, B. Rowe, D. Adamko, J. Allergy Clin. Immunol. 127 (2011) 757.

[75] A. Roquet, B. Dahlen, M. Kumlin, E. Ihre, G. Anstren, S. Binks, S.E. Dahlen, Am. J. Respir. Crit. Care Med. 155 (1997) 1856. 